\title{
Increased cerebrospinal fluid concentrations of soluble Fas (CD95/Apo-1) in hydrocephalus
}

\author{
U Felderhoff-Mueser, R Herold, F Hochhaus, P Koehne, E Ring-Mrozik, M Obladen, \\ C Bührer
}

\begin{abstract}
Background and aims-The ventricular enlargement observed in children with chronically raised intracranial pressure (ICP) causes a secondary loss of brain tissue. In animal studies of hydrocephalus, programmed cell death (apoptosis) has been found as a major mechanism of neuronal injury. One of the regulators of the apoptotic cell death programme is the receptor mediated Fas/Fas ligand interaction.

Methods-The apoptosis regulating cytokines soluble Fas (sFas) and soluble Fas ligand (sFasL) were studied in the cerebrospinal fluid (CSF) of 31 hydrocephalic children undergoing shunt surgery for symptomatic hydrocephalus and 18 controls.

Results-High concentrations of sFas were observed in children with hydrocephalus (median $252 \mathrm{ng} / \mathrm{ml}$ ); in controls sFas was below the detection limit $(0.5$ $\mathrm{ng} / \mathrm{ml})$. sFasL was undetectable in all but one sample.

Conclusion-High concentrations of sFas in the CSF of children with hydrocephalus suggest intrinsic sFas production, potentially antagonising pressure mediated Fas activation.

(Arch Dis Child 2001;84:369-372)
\end{abstract}

Keywords: sFas; sFas ligand; apoptosis; hydrocephalus; ventricular dilatation

Department of

Neonatology, Charité

Children's Hospital,

Virchow Klinikum,

Humboldt University,

Augustenburger

Platz 1, 13353 Berlin,

Germany

U Felderhoff-Mueser

F Hochhaus

P Koehne

M Obladen

C Bührer

Department of

Haematology and

Oncology, Charité

Children's Hospital

R Herold

Department of

Paediatric Surgery,

Klinikum Ingolstadt,

Ingolstadt, Germany

Correspondence to:

Dr Felderhoff-Mueser

ursula.felderhoff@charite.de

Accepted 21 November 2000

and brains, atrophy of the periven white matter, and to some extent the grey matter, as well as damaged axons are consistent findings. Coincident with axonal damage, dying oligodendrocytes and cortical neurones have been found by ultrastructural examination. ${ }^{1-5}$ Several injurious stimuli, such as chronic ischaemia and a combination of mechanical and metabolic factors and loss of appropriate axonal contacts have been implicated in brain tissue loss in hydrocephalus. ${ }^{67}$ In animal studies by Del Bigio and Zhang, cell death in the immature hydrocephalic brain has been suggested both as necrotic and apoptotic. ${ }^{5}$
Thus, hydrocephalus may be added to the growing list of disorders associated with inappropriate cell death in the developing brain, but the molecular mechanisms have not been completely elucidated.

Apoptosis is biochemically and genetically programmed cell death that is distinct from necrosis because it requires time, energy and, in some cases, new gene transcription and translation. A variety of extra- and intracellular signals that regulate the apoptotic cell death programme have been identified. ${ }^{8-10}$ The interaction between the Fas (CD95/Apo-1) cell surface receptor and its death inducing ligand (FasL) play an important role in triggering the apoptotic pathway. ${ }^{11}$ Both Fas and FasL exist as membrane bound and soluble forms. Soluble Fas (sFas) is generated by differential splicing via deletion of an exon encoding the transmembrane domain of Fas. It blocks cell death by inhibiting the interaction between Fas and Fas ligand on the cell surface and thereby serves as an apoptosis regulating protein..$^{12}{ }^{13} \mathrm{In}$ contrast, soluble Fas ligand (sFasL) is generated by proteolytic cleavage of the membrane bound form and is a less potent death inducing cytokine than FasL. ${ }^{14}{ }^{15}$ The regulation of sFas and sFasL synthesis is subject to intensive investigations in cell culture and animal models.

Fas has been detected on a variety of cell types including neuronal cells. In the central nervous system, Fas expression has been shown on neurones, astrocytes, and oligodendrocytes in several disorders. ${ }^{16-19}$ Importantly, Fas upregulation has recently been shown in the adult and in the developing rodent brain following hypoxia-ischaemia. ${ }^{20-22}$ However, the role of the Fas/Fas ligand system in chronic hypoxic states, as present in the hydrocephalic brain remains unclear.

Our aim was to analyse the intrathecal release of $\mathrm{sFas}$ and $\mathrm{sFasL}$ as potentially regulating elements of ongoing apoptotic cell death, and to relate these to clinical findings in hydrocephalus.

\section{Subjects and methods} PATIENT SELECTION

The study was approved by the Ethical Committee of the Ludwig Maximilians University, Munich, Germany.

Ventricular CSF was obtained from 31 chilyears) undergoing shunt surgery between 1996 and 1998. Seven of these patients underwent surgery more than once, so repeated samples were taken (total number of CSF samples: 42). dren (aged 1 month to 16 years, median 7.8 
Table 1 Laboratory findings in the CSF of children with hydrocephalus and in controls

\begin{tabular}{llrll}
\hline & Hydrocephalic children & $n$ & Controls & $n$ \\
\hline sFas $(\mathrm{ng} / \mathrm{ml})$ & $252(103-808)$ & 36 & $<0.5^{\star}$ & 18 \\
& $<0.5^{\star}$ & 6 & & \\
sFasL $(\mathrm{ng} / \mathrm{ml})$ & $<0.1^{\star}$ & 41 & $<0.1^{\star}$ & 18 \\
Protein $(\mathrm{mg} / \mathrm{dl})$ & 298 & 1 & $24.5(21-27.8)$ & 18 \\
Leucocyte count (cells/ $\mu \mathrm{l})$ & $6(1-22)$ & 35 & $2(0-5)$ & 18
\end{tabular}

Results expressed as median (IQR)

${ }^{\star}$ Concentrations were below the detection limit $(<0.5 \mathrm{ng} / \mathrm{ml}$ for sFas, $<0.1 \mathrm{ng} / \mathrm{ml}$ for sFasL).

ICP was measured during surgery. Patients had hydrocephalus associated with spinal dysraphism ( $\mathrm{n}=7)$, intracerebral haemorrhage $(\mathrm{n}=16)$, Arnold-Chiari malformation $(\mathrm{n}=3)$, arthrogryposis multiplex congenita $(\mathrm{n}=1)$, subarachnoid cyst $(\mathrm{n}=1)$, listeria meningitis $(n=1)$, toxoplasmosis $(n=1)$, and brain tumour in remission $(n=1)$. In all patients ventricular dilatation and increased ICP was confirmed by physical examination and neuroimaging.

Patients were evaluated by standardised examination for symptoms of ICP, motor and sensory deficit, peripheral reflexes, ocular fundus, muscular tone, cranial nerve function, and psychomotor development. Increased ICP was initially symptomatic on $36 / 42$ occasions with seizures $(n=21)$, vomiting $(n=26)$, bulging fontanelle $(n=19)$, mental alteration $(n=14)$, headaches $(n=7)$, and papilloedema $(n=7)$. Among patients with previous shunt implantations, shunt dysfunction (16/18) and disconnection $(2 / 18)$ were evident at surgery. In addition, cerebral computed tomography, magnetic resonance imaging, and/or ultrasound scans were obtained before surgery; all patients had ventricular enlargement. No patient had a history of autoimmune or progressive malignant disease.

CSF samples from 18 children without neurological deficit (aged 1 day to 16 years, median 8 years) who underwent lumbar puncture for the exclusion of meningitis served as controls. For practical reasons it was impossible to obtain samples from the same source (ventricular/lumbar CSF) in the study population and in controls. Some controls experienced vomiting $(n=6)$, fever $(n=4)$, singular febrile seizures $(n=2)$, and headaches $(n=1)$. Fundus examination was normal in all controls.

Serum C reactive protein (CRP), ventricular CSF leucocyte count, CSF protein concentration, and bacterial culture were obtained in all subjects.

SFas AND SFas LIGAND ASSAYS

sFas concentrations were determined with a commercial second generation sandwich enzyme linked immunosorbent assay (ELISA; Medical \& Biological Laboratories, Japan) using a polyclonal coating antibody, binding to sFas amino acid residues 305-319, and a monoclonal detecting antibody, binding to residues $110-120$ of spliced sFas at a detection limit of $0.5 \mathrm{ng} / \mathrm{ml}^{12}{ }^{23} \mathrm{sFasL}$ concentrations were determined with a sandwich ELISA (Medical \& Biological Laboratories, Japan) using monoclonal antibodies for coating and

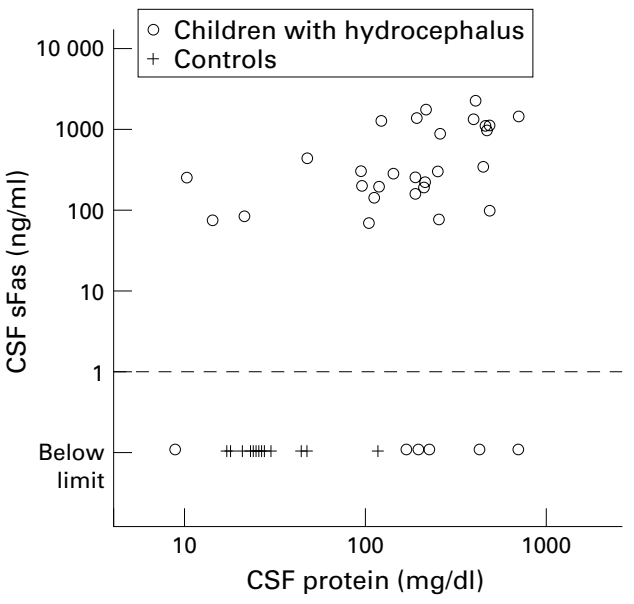

Figure 1 CSF protein content and sFas concentrations in children with hydrocephalus $(n=42)$ and in controls $(n=18)$.

binding (clones $4 \mathrm{H} 9$ and $4 \mathrm{~A} 5$ ) at a detection limit of $0.1 \mathrm{ng} / \mathrm{ml}^{24}$

Protein concentrations in CSF were determined by the micro bicinchoninic acid method. ${ }^{25}$ All assays were performed at least in duplicate. A microplate photometer (Dynatech MR5000, Denkendorf, Germany) was used for analysis of 96 well microtitre plates.

Statistical analyses and graphics were produced with S-Plus 4.5 and entailed univariate statistics, robust statistics, linear regression analysis, and the Mann-Whitney U test for comparing distributions.

\section{Results}

CSF leucocyte counts were low in patients and controls, exceeding 100 per $\mu 1$ in two cases only with hydrocephalus (table 1). Forty eight hour bacterial cultures from all CSF samples were sterile. Serum CRP concentrations were only slightly high, and did not differ in patients (median 0.9 (interquartile range, IQR 0.61.4)) and controls $(0.9(0.6-1.3) \mathrm{mg} / \mathrm{dl})$.

From a total number of 31 patients, 31 initial and 11 repeated samples were taken. sFas concentrations were high in $26 / 31$ and were not detectable in 5/31 initial samples. In 10/11 repeated samples, sFas was high. In controls, neither sFas nor sFasL were detectable (table 1). Restricting the analysis to initial samples did not yield results essentially different from those analysing all samples.

Figure 1 shows the correlation of $\mathrm{sFas}$ concentrations and protein concentrations $\left(r_{s}=0.48, \mathrm{p}=0.02\right)$. sFas did not correlate with CSF leucocyte count $\left(r_{s}=0.3\right)$ or with age $\left(r_{s}=0.4\right)$ (data not shown). In patients with CSF protein concentrations either above or below the median protein concentration (207 $\mathrm{mg} / \mathrm{dl}), \mathrm{sFas}$ concentrations were 71 (184-266) $\mathrm{ng} / \mathrm{ml}(\mathrm{n}=17)$ and $115(497-1019) \mathrm{ng} / \mathrm{ml}$ $(\mathrm{n}=18)$ respectively (difference not significant; $p=0.09)$. In those patients with ventricular CSF leucocyte counts in the range of the control lumbar CSF leucocyte counts $(0-5$ per $\mu l)(n=16)$, sFas concentrations did not differ from $\mathrm{sFas}$ concentrations in patients with increased leucocyte numbers ( $n=19$, $\mathrm{p}=0.23)$. 
sFasL was undetectable in all but one sample of a hydrocephalic patient $(298 \mathrm{ng} / \mathrm{ml})$ with corresponding sFas concentrations of $72 \mathrm{ng} /$ $\mathrm{ml}$.

As there were disparate subgroups of patients included in this study, $\mathrm{sFas}$ was analysed in relation to the underlying diagnoses for hydrocephalus as follows: (1) intracerebral haemorrhage; (2) other cause of mechanical obstruction than haemorrhage (ArnoldChiari, subarachnoid cyst, inflammatory or neoplastic disease). Analysis in the above described subgroups and in all patients did not reveal any significant difference in $\mathrm{sFas}$ and sFasL concentrations.

Furthermore, the magnitude of ICP, as measured during shunt surgery and as indicated by the cited symptoms and the acuity of presentation did not correlate with leucocyte count, or protein, sFas, and sFasL concentrations. In addition, the degree of ventricular enlargement as detected by imaging studies was not related to the concentrations of cytokines or protein, or leucocyte count.

\section{Discussion}

A growing body of evidence points out the role of apoptosis as contributing to brain cell death. It has recently been shown that Fas, one of the key inducers of apoptosis, is upregulated following hypoxia-ischaemia of the developing rat brain. ${ }^{22}$ Our study shows high intrathecal concentrations of the soluble form of Fas (CD95/Apo-1) in the CSF of children with hydrocephalus, a chronic hypoxic-ischaemic event.

sFas, a cytokine with antiapoptotic properties, has been detected in several neurological diseases, particularly in autoimmune disorders, neurodegenerative, and malignant diseases. ${ }^{26-28}$ It has been further identified as a marker in the serum of patients with alcoholic liver disease and chronic obstructive lung disease, indicating a correlation between the severity of the disorder and ongoing apoptotic organ cell death. ${ }^{29} 30$

In a recent study of acute ischaemic brain injury, Tarkowski et al showed decreasing concentrations of $\mathrm{sFas}$ in the CSF of stroke patients during the acute clinical course. In addition, the amount of sFas was negatively correlated with the degree of neurological deficit and with the infarct volume. ${ }^{31}$ The authors suggested an initially high intrinsic production of $\mathrm{sFas}$ to protect residual CNS cells and a subsequently increased receptor mediated consumption of this molecule. In contrast to an acute stroke, hydrocephalus is a chronic event with, in most cases, immediate clinical recovery after reduction of ICP. The findings in stroke patients combined with our observations suggest that in chronic disease states, upregulation of antiapoptotic cytokines might prevent severe damage.

The detection of sFas in the CSF of hydrocephalic children supports the notion of the activation of an intrinsic protection system for brain cells. Moreover, the sFas concentrations detected in the CSF of our patients were well above the previously published $\mathrm{sFas}$ concentrations in CSF and serum in patients with other neurological disorders and in control samples measured with our assay system. ${ }^{27}{ }^{31}{ }^{32}$ There was a discrepancy between the majority of samples containing high concentrations of $s F a s$ and the very few samples below the detection limit. It is assumed that sFas concentrations display a logarithmic distribution, only the top of which is detected by ELISA techniques.

Protein concentrations were higher in patients than in controls. It has to be taken into account that, unavoidably, samples from controls were obtained by lumbar puncture. Gradients certainly exist in various protein and other metabolic factors dependent on the underlying disease. ${ }^{33}$ However, the correlation of sFas concentrations to protein concentrations in both groups indicated that $\mathrm{sFas}$ concentrations are not merely a result of a disturbed blood-brain barrier (fig 1).

Increased sFas concentrations have also been found in the CSF of patients with acute bacterial meningitis but not in patients with viral meningoencephalitis, with invading leucocytes considered to be the main source of sFas. $^{32}$ The lack of a correlation between leucocyte accumulation and $\mathrm{sFas}$ concentrations in the CSF points to central nervous system cells as the main source of sFas production. As neurones, oligodendrocytes, and astrocytes all have the potential to transcribe the Fas gene, the exact origin of $\mathrm{sFas}$ in the hydrocephalic brain remains to be determined. ${ }^{1619}$

Recent studies suggest that the soluble form of the proapoptotic Fas ligand can cause systemic tissue damage with high sFasL concentrations reported in alcoholic liver damage, malignancies, and neurological diseases. ${ }^{24} 2934$ In contrast to Ertel et al, who found sFasL to be increased in the CSF of patients with acute severe head trauma and increased intracranial pressure, ${ }^{34}$ we did not detect any sFasL, except in one patient. Their findings suggest the production of sFasL as an autoregulatory defence mechanism of the host against Fas bearing leucocytes, invading the brain after head injury. ${ }^{34}$ In the hydrocephalic brain there is no significant inflammation, possibly explaining our observations. ${ }^{5}$

None of the previous studies employed the simultaneous measurement of sFas and sFasL. Kinetic studies, possibly in combination with other cytokines, might be helpful for monitoring ongoing brain damage and intrinsic protection systems after an insult.

We conclude that our findings may indicate a propensity towards apoptosis and a pivotal role for the Fas/FasL pathway in the pathophysiology of hydrocephalus. Monitoring of sFas in the CSF might provide additional information in cases where clinical symptoms of raised intracranial pressure are less clear, for example in slit ventricle syndrome. In addition, there is an unfortunate lack of appropriate data on mechanisms of cell death in hydrocephalus; as infants and children with this disorder survive for a long time, neuropathological evidence is rare. Furthermore, animal studies will be 
needed to determine exactly the involvement of apoptosis and the role of the Fas/FasL system in the hydrocephalic brain.

1 Del Bigio MR, da Silva MC, Drake JM, Tuor UI. Acute and chronic cerebral white matter damage in neonatal hydrocephalus. Can 7 Neurol Sci 1994;21:299-305.

2 Mc Allistar JP, Chovan P. Neonatal hydrocephalus: mechanisms and consequences. Neurosurg Clin N Am 1998;9:7393.

3 Harris NG, Jones HC, Patel S. Ventricle shunting in young $\mathrm{H}-\mathrm{Tx}$ rats with inherited congenital hydrocephalus:a quantitative histological study of cortical grey matter. Childs Nerv Syst 1994;10:293-301.

4 Del Bigio MR. Neuropathological changes caused by hydrocephalus. Acta Neuropathol 1993;85:77573-85.

5 Del Bigio MR, Zhang YW. Cell death, axonal damage, and cell birth in the immature rat brain following induction of hydrocephalus. Exp Neurol 1998;154:157-69.

6 Del Bigio MR, Bruni JE, Vriend JP. Monoamine neurotransmitters and their metabolites in the mature rabbit brain following induction of hydrocephalus. Neurochem Res 1998;23:1379-86.

7 Braun KP, de Graaf RA, Vandertop WP, et al. In vivo $1 \mathrm{H}$ $M R$ spectroscopic imaging and diffusion weighted MRI in experimental hydrocephalus. Magn Reson Med 1998;40: 832-9.

8 Wyllie AH, Duvall E. Cell injury and death. In: McGee JO, Isacsson PG, Wright NA eds. Oxford textbook of pathology. Oxford: Oxford University Press, 1992:141-93.

9 Nagata S. Apoptosis by death factor. Cell 1997;88:355-65.

10 Mazarakis ND, Edwards AD, Mehmet H. Apoptosis in neural development and disease. Arch Dis Child Fetal Neonatal Ed 1997;77:F165-70.

11 Nagata S, Golstein P. The Fas death factor. Science 1995;267:1449-56.

12 Cheng J, Zhou T, Liu C, et al. Protection from Fas-mediated apoptosis by a soluble form of the Fas molecule. Science 1994;263:1759-62.

13 Hughes DP, Crispe IN. A naturally occurring soluble isoform of murine Fas generated by alternative splicing. $f$ Exp Med 1995;182:1395-401.

14 Tanaka M, Suda T, Takahashi T, Nagata S. Expression of the functional soluble form of human fas ligand in activated lymphocytes. EMBO F 1995;14:1129-35.

15 Tanaka M, Itai T, Adachi M, Nagata S. Downreglation of Fas ligand by shedding. Nat Med 1998;1:31-6.

16 Cheema ZF, Wade SB, Sata M, et al. Fas/Apo [apoptosis]-1 and associated proteins in the differentiating cerebral cortex:induction of caspase-dependent cell death and activation of NF-kappaB. ₹ Neurosci 1999;19:1754-70.

17 Nishimura $T$, Akiyama $\mathrm{H}$, Yonehara $\mathrm{S}$, et al. Fas antigen expression in brains of patients with Alzheimer-type expression in brains of patients with

18 Dowling P, Shang G, Sumul R, et al. Involvement of the CD95 (APO-1/Fas) receptor/ligand system in the multiple sclerosis brain. F Exp Med 1996;184:1513-18
19 Becher B, D'Souza SD, Troutt AB, Antel JP. Fas expression on human fetal astrocytes without susceptibility to Fas-mediated cytotoxicity. Neuro

20 Matsuyama T, Hata R, Yamamoto Y, et al. Localisation of Fas antigen mRNA induced in postischemic murine forebrain by in situ hybridisation. Mol Brain Res 1995;34: 166-72

21 Martin-Villalba A, Herr I, Jeremias I, et al. CD95 ligand (Fas-L/APO-1L) and tumor necrosis factor-related apoptosis-inducing ligand mediate ischemia-induced apoptosis in neurons. F Neurosci 1999;19:3809-17.

22 Felderhoff-Mueser U, Taylor DL, Greenwood KG, et al. Fas (CD95/Apo-1) can function as a death receptor for neuronal cells in vitro and in vivo and is upregulated following cerebral hypoxic-ischemic injury to the developing rat brain. Brain Pathol 2000;10:19-27.

23 Knipping E, Debatin KM, Stricker K, et al. Identification of soluble APO-1 in supernatants of human B- and T-cell lines and increased serum levels in B- and T-cell leukemias. Blood 1995;85:1562-9.

24 Sato K, Kimura F, Nakamura Y, et al. An aggressive nasal lymphoma accompanied by high levels of soluble Fas ligand. Br f Haematol 1996;94:379-82.

25 Smith PK, Krohn RI, Hermanson GT, et al. Measurement of protein using bicinchoninic acid. Anal Biochem 1995; 150:76-85.

26 Mogi M, Harada M, Kondo T, et al. The soluble form of Fas molecule is elevated in parkinsonian brain tissues. Neurosci Lett 1996;220:195-8.

27 Zipp F, Otzelberger K, Dichgans J, et al. Serum CD95 of relapsing remitting multiple sclerosis patients protects from CD95-mediated apoptosis. 7 Neuroimmunol 1998;86: 151-4.

28 Streffer JR, Schuster M, Zipp F, Weller M. Soluble CD95 Fas/APO-1) in malignant glioma: (no) implications for CD95-based immunotherapy? f Neurooncol 1998;40: 233-5.

29 Taieb J, Mathurin P, Poynard T, et al. Raised plasma soluble Fas and Fas-ligand in alcoholic liver disease. Lancet 1998:351:1930-1.

30 Yasuda N, Gotoh K, Minatoguchi S, et al. An increase of soluble Fas, an inhibitor of apoptosis, associated with progression of COPD. Respir Med 1998;92:993-9.

31 Tarkowski E, Rosengren L, Blomstrand C, et al. Intrathecal expression of proteins regulating apoptosis in acute stroke. Stroke 1999;30:321-7.

32 Fassbender K, Eschenfelder C, Hennerici M. Fas (Apo-1/ CD95) in inflammatory CNS diseases:intrathecal release in bacterial meningitis. F Neuroimmunol 1999;93:122-5.

33 Gerber J, Tumani H, Kolenda H, Nau R. Lumbar and ventricular CSF protein, leukocytes, and lactate in suspected
bacterial CNS infections. Neurology 1998;51:1710-14.

34 Ertel W, Keel M, Stocker R, et al. Detectable concentrations of Fas ligand in cerebrospinal fluid after severe head injury. 7 Neuroimmunol 1997;80:93-6.

35 Inoue A, Koh CS, Sakai T, et al. Detection of the soluble form of the Fas molecule in patients with multiple sclerosis and human T-lymphotropic virus type I-associated myelopathy. $\mathcal{F}$ Neuroimmunol 1997;75:141-6. 